delegates have been appointed to attend from almost all civilised countries. It was a fortunate chance that the dates arranged for an international conference on nuclear physics under the auspices of the Physical Society should have coincided with those of a proposed meeting in London of the International Union of Pure and Applied. Physics; the fusion of the two meetings into a joint conference has resulted in a programme of absorbing interest and importance. On October 1 there are meetings of the executive committee of the International Union of Physics and of its Commission on Symbols, Units and Nomen. clature (S.U.N.). On October 2-5, the sessions of the Conference will be divided between discussions on the solid state and on nuclear physics, under the presidencies of Lord Rayleigh and Prof. R. A. Millikan respectively. Opening surveys will be given by Sir William Bragg and Lord Rutherford. Meetings will take place at the Royal Institution, at the Royal Society and at Cambridge. The afternoon session of October 5, to be held at the Royal Institution, will receive the report of the S.U.N. Commission, and the meeting on October 6 at the same place will consider a communication concerning Dr. Hale's Committee on Instruments, discuss future work of the S.U.N. Commission and other business, concluding with a final meeting of the executive committee of the International Union of Physics. Titles of papers to be read will be found in our columns of "Forthcoming Events".

THE programme includes several social events of interest. The Royal Society is holding a reception on Tuesday evening, and a visit will be paid to the National Physical Laboratory on Saturday afternoon. Some of the sessions on nuclear physics will, most appropriately, be held at Cambridge, and the members of the Conference visiting Cambridge are invited to lunch at Trinity College and to tea at the Cavendish Laboratory. The major portion of the scientific sessions will be devoted to papers and discussions on the solid state and on nuclear physics ; but the work assigned to Friday afternoon and Saturday morning, covering as it does certain proposals concerning symbols, units and nomenclature, is of considerable importance in the present confused state of affairs, and it is greatly to be desired that the findings of the Commission will result in a much needed approach to uniformity in definitions and nomenclature. The report of the Conference will appear soon after the meeting. The more important papers will be published in extenso, and the report should prove a valuable record of a historic conference.

\section{Japanese Typhoon of September 21}

A Typhoon that is reported in the daily Press to have passed across the south-western parts of Japan on September 21, and to have maintained its intensity there for a whole day, with winds up to about 130 miles an hour, is said to have been the most destructive tropical storm of this type that has visited Japan since 1917. In the Times of September 26 , it is stated that the Japanese Home Office on
September 25 gave the casualties as 2,305 killed, 7,839 injured and 399 missing, with a total of more than 34,576 houses totally destroyed and more than ten times that number washed away, and some 3,000 ships damaged. Information about the meteorological aspects of the typhoon is scanty. The cyclone season in that neighbourhood virtually covers the whole year, although storms are very rare in February and March. As Japan lies altogether north of latitude $30^{\circ}$, a typhoon that reaches that country is approaching the stage when it becomes a cyclonic depression of temperate latitudes, and having 'recurved', is generally moving north or north-east. This would account perhaps for the south-west of Japan being affected, but the northeast comparatively little. September is the month of greatest frequency of typhoons, and there is a rapid falling off in the last three months of the year. During the recent storm, trains were derailed, among which was the Tokyo-Shimonoseki express, which, with 250 passengers on board, left the rails while crossing a bridge, to be held fortunately by the parapet. There seem to have been the usual seawaves, which penetrated far inland, and enough rain to cause serious flooding after the storm had abated. The track is said to have been from Nagasaki in the extreme south-west to the neighbourhood of Wakasa Bay, about four hundred miles to the north-east, Tokyo fortunately escaping with minor damage only.

\section{German Association of Men of Science and Physicians}

Favoured by the continued fine weather, the Gesellschaft Deutscher Naturforscher und Aerzte held its ninety-third meeting on September 16-20 in Hanover, well-known as the home of Leibniz. The attendance of some four thousand found a wide range of topies awaiting their consideration, for thirty allied societies also took part in the proceedings. Among these may be mentioned the Deutsche Chemische Gesellschaft, which contributed half a dozen papers, including one from Prof. The Svedberg on the applications of the ultra-centrifuge, and the Kolloid-Gesellschaft, which for its tenth general meeting devoted two very full days to "Röntgenoskopie und Elektronoskopie von dispersen Systemen, Faden, Filmen und Grenzschichten". In addition to the more specialised discussions within the two main divisions of natural science and medicine, there were combined discussions and discourses of wider appeal addressed to the meeting as a whole, after the manner of the British Association. Among the last-mentioned, particular interest was aroused by Prof. W. Heisen. berg's lecture, "Wandlungen der Grundlagen der exakten Naturwissenschaften in jüngster Zeit", in much the same field as that covered by Sir James Jeans's address at Aberdeen. An exhibition of apparatus, preparations and scientific books was held in the Ausstellungshalle, one of scientific films in the Tierärztliche Hochschule, and another, the travelling exhibition of the Dresden Museum of Hygiene, "Leben und Gesundheit", in the Künstlerhaus, while lighter moments were provided for by the Opera House and theatre and the usual excursions to neighbouring centres of attraction. 